\title{
Bio-hydrogen production from waste materials: A review
}

\author{
Vinod Singh Yadav ${ }^{1, *}$, Vinoth $\mathrm{R}^{2}$, Dharmesh Yadav $^{2}$ \\ ${ }^{1}$ Mechanical Engineering, NIT, Uttarakhand, Srinagar, India \\ ${ }^{2}$ Automobile Engineering, SAMM, Manipal University, Jaipur, India
}

\begin{abstract}
When hydrogen burns in air, it produces nothing but water vapour. It is therefore the cleanest possible, totally non-polluting fuel. This fact has led some people to propose an energy economy based entirely on hydrogen, in which hydrogen would replace gasoline, oil, natural gas, coal, and nuclear power. Hydrogen is a clean energy source. Therefore, in recent years, demand on hydrogen production has increased considerably. Electrolysis of water, steam reforming of hydrocarbons and auto-thermal processes are well-known methods for hydrogen gas production, but not cost-effective due to high energy requirements. As compare to chemical methods, biological production of hydrogen gas has significant advantages such as bio-photolysis of water by algae, dark and photo-fermentation of organic materials, usually carbohydrates by bacteria. New approach for bio-hydrogen production is dark and photo-fermentation process but with some major problems like dark and photo-fermentative hydrogen production is the raw material cost. By using suitable bio-process technologies hydrogen can be produced through carbohydrate rich, nitrogen deficient solid wastes such as cellulose and starch containing agricultural and food industry wastes and some food industry wastewaters such as cheese whey, olive mill and baker's yeast industry wastewaters. Utilization of aforementioned wastes for hydrogen production provides inexpensive energy generation with simultaneous waste treatment. This review article summarizes bio-hydrogen production from some waste materials with recent developments and relative advantages.
\end{abstract}

\section{Introduction}

The energy need has been increasing exponentially all over world-wide, the reserves of fossil fuels are going to deplete very soon in near future, and serious negative effects of the combustion of fossil fuels are spreading throughout because of $\mathrm{CO}_{2}$ emission is growing day by day in the atmospheric air. For such types of reasons, motivating the researchers to find some kind of new sustainable energy sources those should be capable to substitute the conventional energy sources with less emissions.

The major demerits in utilization of hydrogen as a gaseous fuel is its availability in nature is nil or can say not easy and expensive production methods are required. It has been reported that 50 million tonnes of hydrogen are traded annually worldwide with a growth rate of nearly $10 \%$ per year for the time being [1]. Based on the National Hydrogen program of the United States, the contribution of hydrogen to total energy market will be $8-10 \%$ by 2025 [2]. It was reported by the US Department of Energy (US-DOE) that $\mathrm{H} 2$ power and transport systems will be available in all regions of the United States by the year 2040 [3]. Due to this level of increasing need for hydrogen energy, in recent years there is urgent need to pay attention on finding the costeffective development and efficient hydrogen production technologies.

Some methods are developed to improve the existing technologies like, membrane processes, selective oxidation of methane and oxidative dehydrogenation [2]. Biomass and water can be used as renewable resources for hydrogen gas production. Utilization of wide variety of gaseous, liquid and solid carbonaceous wastes was investigated by Kim [4] as renewable sources for formation of hydrogen gas by steam reforming. Despite the low cost of waste materials used, high temperature requirement $\left(\mathrm{T}=1200{ }^{\circ} \mathrm{C}\right)$ is still the major limitation for this process. Electrolysis of water may be the cleanest technology for hydrogen gas production. However, electrolysis should be used in areas where electricity is inexpensive since electricity costs account for $80 \%$ of the operating cost of $\mathrm{H}_{2}$ production. In addition, feed water has to be demineralized to avoid deposits on the electrodes and corrosion [2].

Photosynthetic processes include algae which use $\mathrm{CO}_{2}$ and $\mathrm{H}_{2} \mathrm{O}$ for hydrogen gas production. Some photoheterotrophic bacteria utilize organic acids such as acetic, lactic and butyric acids to produce $\mathrm{H}_{2}$ and $\mathrm{CO}_{2}$. However, the rate of $\mathrm{H}_{2}$ production is low and the technology for this process needs further development [5].

With the use of sustainable technologies production of clean energy source and utilization of waste materials make biological hydrogen production a novel and promising approach to meet the increasing energy needs.

\section{Types of waste materials}

Availability, cost, carbohydrate content and biodegradability are the major concern for the selection of waste materials from which bio-hydrogen is going to be produced. Pure carbohydrate sources are expensive raw materials.

\subsection{Carbohydrate industrial wastewaters}

Some biodegradable carbohydrate containing and nontoxic industrial effluents such as dairy industry, olive

* Corresponding author: vinodsingh.yadav@jaipur.manipal.edu 
mill, baker's yeast and brewery wastewaters can be used as raw material for bio-hydrogen production [6]. To remove undesirable components and for nutritional balancing, pre-treatment of waste waters may require. Fig. 1 shows schematic diagram for bio-hydrogen production from food industry wastewaters by two stage anaerobic dark and photo-fermentations.

\subsection{Waste sludge of WTP}

For production of methane or hydrogen gas, large quantities of carbohydrate and proteins are useful which can be available from waste sludge generated in wastewater treatment plants.

\subsection{Agricultural or food industry wastes (Starch and cellulose)}

Biodegradability may be affected badly due to the complex nature of these types of wastes. Cellulose containing agricultural wastes requires further pretreatment. Agricultural wastes should be ground and then de-lignified by mechanical or chemical means before fermentation.

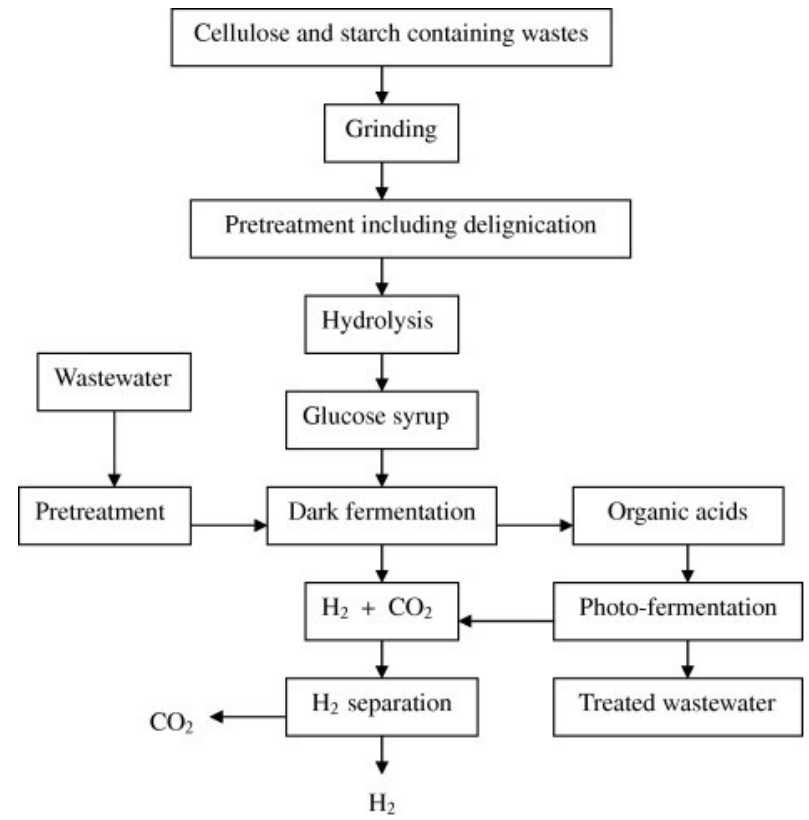

Fig. 1: Bio-hydrogen production from agriculture and food industry wastewaters by two stage anaerobic dark and photo-fermentations

\section{Bio-processes for hydrogen gas production}

For hydrogen gas production, three major categories can be classified:

1. Bio-photolysis of water through algae.

2. Dark/photo-fermentative (two stage) hydrogen production.

3. Dark-fermentative hydrogen production during acidogenic phase of anaerobic digestion of organic matter.

\subsection{Bio-photolysis of water through algae}

Generally, the work of algae is division of water molecules into hydrogen ion and oxygen via photosynthesis process. By the use of hydrogenase enzyme, hydrogen ions can be converted in hydrogen gas. Chlamydomonas reinhardtii is one of the wellknown hydrogen producing algae [7,8]. Hydrogenase activity has been detected in green algae, Scenedesmus obliquus [9], in marine green algae Chlorococcum littorale [10,11], Playtmonas subcordiformis [12] and in Chlorella fusca [13]. The hydrogenase activity of different algae species was compared by Winkler et al. [14] and it was reported that enzyme activity of the Scenedesmus sp. (150 nmol/_g Chl a.h) is lower than C. reindhartii (200 nmol/_g Chl a.h). It was reported that Anabaena sp. have higher hydrogen evolution potential over the other cyanobacter species [15]. Four to $18 \%$ $\mathrm{CO}_{2}$ concentrations were reported to increase cell density during growth phase resulting in higher hydrogen evolution in the later stage [16].

\subsection{Hydrogen gas production through photo- fermentations (two stage)}

\subsubsection{Types of organisms with conditions}

Hydrogen gas production capabilities of some purple photosynthetic bacteria such as Rhodobacter spheroides [17,18-27], Rhodobacter capsulatus [29], Rhodovulum sulfidophilum W-1S and Rhodopseudomonas palustris have been investigated. Photoproduction of hydrogen from $\mathrm{CO}$ or other organic acids by carbon-monoxide dependent dehydrogenase (CODH) enzyme containing cultures such as Rhodospirillum rubrum and Rodopseudomonos palsutris P4 has also been investigated.

Therefore, the process requires ammonium limited and oxygen free conditions. Hydrogen gas production was lower in the presence of ammonia salts, while proteins such as albumin, glutamate and yeast extract as a nitrogen source enhanced the production. The metabolism shifts to utilization of organic substance for cell synthesis rather than hydrogen production in the presence of high nitrogen concentrations resulting in excess biomass growth and reduction in light diffusion [27]. It was reported that presence of carbonate enhanced ammonia removal and stimulated hydrogen production. Light intensity is one of the parameters which affects the performance of photofermentation. Increasing light intensity has a stimulatory effect on hydrogen yield and production rate, but has an adverse effect on the light conversion efficiency [29]. Light intensity might also affect the consumption rates of organic acids. Similarly, Wakayama reported that hydrogen production rate during $30 \mathrm{~min}$ dark/light cycle was $22 \mathrm{~L} / \mathrm{m} 2 \mathrm{~d}$ which was twice as much as that obtained by illuminated culture during a $12 \mathrm{~h}$ cycle under the same condition.

\subsubsection{Substrates}


Utilization of industrial effluents for hydrogen gas production by photosynthetic bacteria is possible although, these cultures prefer organic acids as carbon sources. Color of wastewaters is the one of the effluents, which could reduce the light penetration. Hydrogen gas production from potato starch, sugar cane, juice and whey by using Rhodopseudomonas sp. Was investigated by Singh Among the three substrates sugar cane juice yielded the maximum level of hydrogen production (45 $\mathrm{mL} / \mathrm{mg} \mathrm{DWh}$ ) as compared to potato $(30 \mathrm{~mL} / \mathrm{mg} \mathrm{DWh})$ and whey (25 mL/mg DWh)[29].

\subsubsection{Bio-hydrogen production via Photo-bioreactors}

Tubular, flat panel and bubble column reactors are the major types of photo-bioreactors developed for hydrogen production. A mutant type photosynthetic bacteria have been developed to increase the light conversion efficiency and hence hydrogen production rate.

El-Shishtawy reported $9.23 \%$ maximum light conversion efficiency by using light-induced and diffused photobioreactor (IDPBR) at $300 \mathrm{~W} / \mathrm{m}^{2}$ light intensity. The width of the culture significantly affected the productivity which reached to $7577 \mathrm{~mL} \mathrm{H}_{2} / \mathrm{m}^{2} \mathrm{~h}$ hydrogen production rate with $1 \mathrm{~cm}$ culture width was investigated by Nakada in a photo-bioreactor composed of four compartments aligned along the light penetration axis. In addition, a delay of $2-4 \mathrm{~h}$ was observed in maximum hydrogen production rate $\left(3.4 \mathrm{~L} \mathrm{H}_{2} / \mathrm{m}^{2} \mathrm{~h}\right)$ after the highest light intensity at noon with an average light conversion efficiency of $1.4 \%$.

\subsection{Dark-fermentative hydrogen production during acidogenic phase of anaerobic digestion of organic matter}

\subsubsection{Type of organisms with conditions}

Hydrogen can be produced through many anaerobic organisms from carbohydrate containing organic wastes. Investigations on microbial diversity of a mesophilic hydrogen producing sludge indicated the presence of Clostridia species as $64.6 \%$. By mixed acid or the 2-3 butanediol fermentation, $\mathrm{CO}_{2}$ and $\mathrm{H}_{2}$ are produced from formic acid in addition to ethanol and the 2-3 butanediol. Recently, researchers identified hydrogen producing aerobic cultures such as Aeromonos spp., Pseudomonos spp. and Vibrio spp. Under anaerobic conditions when the cultures were cultivated, the hydrogen yield varied between 1 and $1.2 \mathrm{mmol} / \mathrm{mol}$ glucose. Hydrogen production by Thermotogales species and Bacillus sp. were detected in mesophilic acidogenic cultures.

Medium $\mathrm{pH}$ affects biogas content, hydrogen production yield, the specific hydrogen production rate, and type of the organic acids produced. $\mathrm{pH}$ range for the maximum hydrogen yield or specific hydrogen production rate is reported between $\mathrm{pH} 5.0$ and 6.0. However, the optimum $\mathrm{pH}$ range is reported by some investigators in between 6.8 and 8.0. Most of the studies indicated that final $\mathrm{pH}$ in anaerobic hydrogen production is around 4.0-4.8 regardless of initial $\mathrm{pH}$. Due to production of organic acids which depletes the buffering capacity of the medium results in decrease in $\mathrm{pH}$. Gradual decreases in $\mathrm{pH}$ inhibit hydrogen production since $\mathrm{pH}$ affects the activity of iron containing hydrogenase enzyme.

When lactose and molasses (sucrose) were used as the substrates, formation of lactic acid was observed. $\mathrm{pH}$ also affects the type of organic acids produced. Concentration of acetate and butyrate could be almost equal at $\mathrm{pH}$ 6.5-7.0. Ethanol production was observed depending on the environmental conditions. Methane was not detected in most of the hydrogen production studies because of elimination of methane producers by heat digestion of sludge. However, long retention times may cause methane formation by the mesophilic cultures. Methane production was also observed when sewage sludge was used as the substrate.

\subsubsection{Substrates}

\subsubsection{Use of simple sugars}

An easily biodegradable carbon source is Glucose which is present in most of the industrial effluents and can be obtained abundantly from agricultural wastes. The highest hydrogen yield obtained from glucose is around 2.0-2.4 $\mathrm{mol} / \mathrm{mol}$. Though, even when more than $95 \%$ glucose was degraded, the yield could be less than 1.7 mol $\mathrm{H}_{2} / \mathrm{mol}$ glucose. Therefore, utilization of substrate as an energy source for bacterial growth is the main reason for obtaining the yields lower than theoretical estimations. Similarly, cumulative hydrogen production from sucrose was $300 \mathrm{~mL}$ while it was only $140 \mathrm{~mL}$ from starch. These studies showed that the higher hydrogen yields could be obtained from sucrose compared to other simple sugars.

\subsubsection{Use of starch containing wastes.}

As a carbohydrate source for hydrogen production, starch containing materials are abundant in nature and have great potential to be used. As per the reaction stoichiometry, a maximum of $553 \mathrm{~mL}$ hydrogen gas is produced from one gram of starch with acetate as a byproduct.

\subsubsection{Use of cellulose containing wastes.}

The major constitute of plant biomass and highly available in agricultural wastes and industrial effluents such as pulp/paper and food industry is Cellulose. If cellulose concentration increases, it resulted in lower yields with the maximum value of $2.18 \mathrm{~mol} \mathrm{H}_{2} / \mathrm{mol}$ cellulose with $12.5 \mathrm{~g} / \mathrm{L}$ cellulose concentration.

During an $81 \mathrm{~h}$ period of stationary culture, the organisms consumed $0.92 \mathrm{mmol}$ glucose $/ \mathrm{h}$ and produced $4.10 \mathrm{mmol} \mathrm{H}_{2} / \mathrm{h}$. The hydrogen yield from the hydrolysate was higher than that of carbohydrates as 19.6 and $18.6 \mathrm{mmol} \mathrm{H}_{2}$ per gram of substrate consumed, respectively.

\subsubsection{Use of food industry wastes and wastewater.}

The conventional approaches for the solid waste management are landfilling, composting and 
incineration. The variations in carbohydrate and protein types and concentrations in the mixture is the problem with the food waste. Each component requires different environmental and bio-processing conditions for hydrogen gas production.

Addition of sewage sludge onto food waste as a rich protein source did not improve the production rate. Similarly, hydrogen production potential of carbohydrate rich high solid organic waste (HSOW) was 20 times larger than those of fat rich HSOW and protein rich HSOW because of the consumption of hydrogen gas to form ammonium using nitrogen generated from biodegradation of protein rich solid wastes.

\subsubsection{Use of waste sludge.}

Biosolids (sludges) from waste water treatment plants contain large amounts of polysaccharides and proteins. Hydrogen yields of $1.2 \mathrm{mg} \mathrm{H} / \mathrm{g} \mathrm{COD}$ and $0.6 \mathrm{~mol} / \mathrm{kg}$ CODi were reported when sludge was used as the raw material. However, higher hydrogen yields $(15 \mathrm{mg} \mathrm{H} / \mathrm{g}$ COD) were obtained from the filtrate.

\subsection{Hydrogen gas production by sequential dark and photo-fermentation}

A new approach in biological hydrogen gas production is sequential dark and photo-fermentation. The limitation by the organic acid availability would be removed. Higher hydrogen production yields can be attained when two systems are combined. Further, utilization of organic acids by photo-fermentative bacteria could offer better effluent quality in terms of COD. The ammonia concentration and $\mathrm{C} / \mathrm{N}$ ratio in the effluent of anaerobic fermentation should not be at the inhibitory level for the photosynthetic bacteria. Dilution and neutralization of dark fermentation effluents are required before photofermentation to adjust the organic acid concentration and the $\mathrm{pH} 7$ for the optimal performance of photosynthetic bacteria.

\section{Conclusions}

Hydrogen is considered as the 'energy for future' since it is a clean energy source with high energy content as compared to hydrocarbon fuels. Therefore, new processes need to be developed for cost-effective production of hydrogen. Chemical methods such as steam reforming of hydrocarbons and partial oxidation of fossil fuels operate at high temperatures, and therefore are energy intensive and expensive.

Biological methods offer distinct advantages for hydrogen production such as operation under mild conditions and specific conversions. However, raw material cost is one of the major limitations for biohydrogen production. Utilization of some carbohydrate rich, starch or cellulose containing solid wastes and/or some food industry wastewaters is an attractive approach for bio-hydrogen production.

Among the various methods used for bio-hydrogen production are: (a) water splitting by photosynthetic algae, (b) dark fermentation of carbohydrate rich wastes and (c) photofermentation of organic acid rich wastewaters. Organic acids produced during the dark fermentation of carbohydrate rich wastes may be converted to hydrogen and $\mathrm{CO}_{2}$ by photoheterotrophic bacteria. The process requires special organisms, light and strict control of the environmental conditions. Sequential or combined bio-processes of dark and photofermentations seem to be the most attractive approach resulting in high hydrogen yields for hydrogen production from carbohydrate rich wastes.

The major problems in bio-hydrogen production from wastes are the low rates and yields of hydrogen formation. Large reactor volumes are required for biohydrogen production due to low hydrogen production rates. Low yields and the rates of hydrogen formation may be overcome by selecting and using more effective organisms or mixed cultures, developing more efficient processing schemes, optimizing the environmental conditions, improving the light utilization efficiency and developing more efficient photo-bioreactors. Considerable research and development studies are needed to improve the 'state of the art' in bio-hydrogen production.

\section{References}

[1] Winter CJ. Into the hydrogen energy economymilestones. International Journal of Hydrogen Energy 2005;30:681-5.

[2] Armor JN. The multiple roles for catalysis in the production of H2. Appl Catal A: Gen 1999;176:159-76.

[3] United States Department of Energy. An integrated research, development and demonstration plan. Hydrogen Pasteur Plan, 2004.

[4] Kim HY. A low cost production of hydrogen from carbonaceous wastes. International Journal of Hydrogen Energy 2003;28:1179-86.

[5] Levin DB, Pitt L, Love M. Biohydrogen production: prospects and limitations to practical application. International Journal of Hydrogen Energy 2004;29:17385 .

[6] De Vrije T, De Haas GG, Tan GB, Keijsers ERP, Claassen PAM. Pretreatment of Miscanthus for hydrogen production by Thermotoga elfii. International Journal of Hydrogen Energy 2002;27:1381-90.

[7] Ghirardi ML, Zhang L, Lee JW, Flynn T, Seibert M, Greenbaum E, et al. Microalgae: a green source of renewable H2. Tibtech 2000;18:506-11.

[8] Melis A. Green alga hydrogen production: progress, challenges and prospects. International Journal of Hydrogen Energy 2002;27:1217-28.

[9] Florin L, Tsokoglou A, Happe T. A novel type of iron hydrogenase in the green alga Scenedesmus obliquus is linked to the photosynthetic electron transport chain. J Biol Chem 2001;276:6125-32.

[10] Ueno Y, Kurano N, Miyachi S. Purification and characterization of hydrogenase from the marine green alga, Chlorococcum littorale. FEBS Lett 1999;443:1448.

[11] Schnackenberg J, Ikemoto H, Miyachi S. Photosynthesis and hydrogen evolution under stress 
conditions in a CO2-tolerant marine green alga, Chlorococcum littorale. J Photochem Photobiol B: Biol 1996;34:59-62.

[12] Guan Y, Deng M, Yu X, Zang W. Two stage photoproduction of hydrogen by marine green algae Platymonas subcordiformis. Biochem Eng J 2004;19:6973.

[13] Winkler M, Heil B, Heil B, Happe T. Isolation and molecular characterization of the $[\mathrm{Fe}]$-hydrogenase from the unicellular green alga Chlorella fusca. Biochim Biophys Acta (BBA): Gene Struct Express 2002;1576:330-4.

[14] Winkler M, Hemschemeier A, Gotor C, Melis A, Happer T. [Fe]- hydrogenases in green algae: photofermentation and hydrogen evolution under sulfur deprivation. International Journal of Hydrogen Energy 2002;27:1431-9.

[15] Pinto FAL, Troshina O, Lindbald P. A brief look at three decades of research on cyanobacterial hydrogen evolution. International Journal of Hydrogen Energy 2002;27:1209-15.

[16] Yoon JH, Sim SJ, Kim M, Park TH. High cell density culture of Anabaena variabilis using repeated injection of carbon dioxide for the production of hydrogen. International Journal of Hydrogen Energy 2002;27:1265-70.

[17] Koku H, Ero glu 'I, G“und“uz U, Y“ucel M, T“urker L. Aspects of metabolism of hydrogen production by Rhodobacter sphaeroides. International Journal of Hydrogen Energy 2002;27:1315-29.

[18] Federov AS, Tsygankov AA, Rao KK, Hall DO. Hydrogen photoproduction by Rhodobacter sphaeroides immobilized on polyurethane foam. Biotechnol Lett 1998;20:1007-9.

[19] Ero ־lu 'I, Aslan K, G“und“uz U, Y“ucel M, T“urker L. Substrate consumption rate for hydrogen production by Rhodobacter sphaeroides in a column photobioreactor. J Biotechnol 1999;70:103-13.

[20] Koku H, Ero־glu 'I, G“und“uz U, Y“ucel M, T“urker L. Kinetics of biohydrogen production by the photosynthetic bacterium Rhodobacter spheroids O.U. 001. International Journal of Hydrogen Energy 2003;28:381-8.

[21] Ero glu E, G“und"uz U, Y“ucel M, T"urker L,

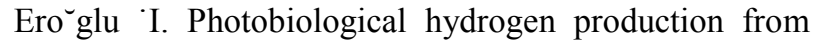
olive mill wastewater as sole substrate sources. International Journal of Hydrogen Energy 2004;29:16371.

[22] Yetis M, G“und"uz U, Ero־glu 'I, Y“ucel M, T“urker L. Photoproduction of hydrogen from sugar refinery wastewater by Rhodobacter sphaeroides O.U.001. International Journal of Hydrogen Energy 2000;25:1035-41.

[23] Kondo T, Arakawa M, Hiral T, Wakayama T, Hara M, Miyake J. Enhancement of hydrogen production by a photosynthetic bacterium mutant with reduced pigment. J Biosci Bioeng 2002;93:145-50.

[24] Kim MS, Baek JS, Lee JK. Comparison of H2 accumulation by Rhodobacter sphaeroides KD131 and its uptake hydrogenase and PHB synthase deficient mutant. International Journal of Hydrogen Energy 2006;31:121-7.
[25] Zhu H, Ueda S, Asada Y, Miyake J. Hydrogen production as a novel process of wastewater treatmentstudies on tofu wastewater with entrapped R. sphaeroides and mutagenesis. International Journal of Hydrogen Energy 2002;27:1349-57.

[26] Zhu H, Suzuki T, Tsygankov AA, Asada Y. Miyake J. hydrogen production from tofu wastewater by Rhodobacter sphaeroides immobilized agar gels. International Journal of Hydrogen Energy 1999;24:30510 .

[27] Fascetti E, Todini O. Rhodobacter sphaeroids RV cultivation and hydrogen production in a one and two stage chemostat. Appl Microbial Biotechnol 1995;44:300-5.

[28] He D, Bultel Y, Magnin JP, Roux C, Willison JC. Hydrogen photosynthesis by Rhodobacter capsulatus and its coupling to PEM fuel cell. J Power Sources 2005;141:19-23.

[29] Fang HHP, Liu H, Zhang T. Phototrophic hydrogen production from acetate and butyrate in wastewater. International Journal of Hydrogen Energy 2005;30:78593. 